\title{
Effects of Exemplars, Affinity and Affect on Reactions to Presidential Elec- tion Stories
}

\author{
Shuhua Zhou* \\ 432C Reese Phifer, Dept. of Telecommunication, University of Alabama, Tuscaoosa, AL. 35487, USA
}

\begin{abstract}
Affective reaction is a little researched area in political news. This study examined three factors that might generate affective responses in addition to the candidates themselves: the use of exemplars in television stories, the valence of story content and the affinity of audience members toward candidates. A within subject experiment was conducted. Results indicated that candidates and valence had main effects on affective responses, whereas exemplars and affinity did not. Exemplification affected perceived believability of stories, but not perceived informativeness and professionalism. Implications were discussed.
\end{abstract}

\section{INTRODUCTION}

Charges of news bias have never subsided since the advent of television. In fact, it is presumed that news coverage is always "biased" even when journalists try hard to be objective (Gans, 1979). After all, neither they nor anyone else can proceed without values. However, people are concerned about the selectivity of news because television creates an instantaneous network in which millions are simultaneous recipients of the same messages. Given television's ability to shape reality, presidential candidates have learned to adapt to the medium. Studies on presidential elections have demonstrated that the news media do exert some fairly significant influences over the outcomes (Hansen \& Benoit, 2007; Just, 1996; Pfau, 2002).

This paper focuses on the selectivity of exemplars in the last US presidential election, which should offer valuable insight to the current 2008 presidential election. Exemplars are concrete information about individuals whose experience illustrates the ramifications of particular issues. Ideally, exemplars should be selected based on some pertinent properties of the issues. However, reporters do not always select typical cases based on stringent criteria. Instead, cases are often chosen for their dramatic and sensational values rather than their accurate reflection on the political issues. Because exemplars are concrete incidents, they can force attention and impose themselves from memory. Given this superior accessibility, exemplars exert disproportional influence on the perception and assessment of political candidates.

However, it'd be naïve to assume that exemplars exert uniform effects. Apparently, all audience members will not react in the same way to all exemplars. In a hotly contested presidential election, the selection of positive exemplars espousing one candidate often means negative reflection on the other. As such, audience reaction to the candidates in the exemplified stories may be very differently, depending on their affinity to the candidates. Two forces are at play here,

*Address correspondence to this author at $432 \mathrm{C}$ Reese Phifer, Dept. of Telecommunication, University of Alabama, Tuscaoosa, AL. 35487, USA; Tel: 205-348-8653; Fax No.: 205-348-5162; E-mail: szhou@ @ama.ua.edu one being the affect of the exemplars, or whether it's a positive exemplar or a negative one to a particular candidate, the other being the affinity of the audience members to the exemplified, or the degree of like or dislike toward the candidates.

Research on news exemplars usually focus on the effects of biased judgment of reality (Zillmann \& Brosius, 2000), and is seldom coupled with political affect to see its influences in the political process. In addition, the affinity of audience members toward candidates is often overlooked. This study, therefore, tries to understand the affect embedded in the exemplars and the dispositional affinity of the audience members to investigate how they interact to induce reaction toward political candidates.

\section{LITERATURE REVIEW}

\section{Exemplar}

The concept of exemplar has been explicated comprehensively by Zillmann and Brosius (2000). An exemplar can be an individual, his situation, events happening to him or what he says if it exemplifies shared group attributes. In political news, journalists often use exemplars to illustrate a particular assertion or a controversial social issue. In a story about casualty in Iraq and its traumatic effect on a family, for example, reporters often use the death of a particular soldier to illustrate the hardship his family goes through, rather than using summary statistics to discuss the issue.

Because human beings are cognitive misers (Eysenck, 2001), exemplars offer heuristics to simplify and expedite information intake and utilization. This process is especially pertinent in political and social issues where evaluation and judgments are often made without apparent elaboration. As such, the effects of exemplars in the media are often inflated because media time and space are limited and audience members are limited to the bits and pieces of information journalists can provide (Zillmann \& Brosius, 2000). Research has shown that exemplars lead media consumers to overestimate incidence rates (Gibson \& Zillmann, 1994; Perry \& Gonzenbach, 1997; Zillmann, 2006; Zillmann, Perkins, \& Sundar, 1992). Although results varied according to 
different study orientations and manipulations, conclusions drawn from these studies are almost uniform: exemplars have a strong impact on people's belief and perceptions (Brosius, 2003).

Research on the characteristics of exemplars often focus on their vividness and salient nature to explain effects. These two concepts are related and they both ascribe to a central role to attention (Zillmann \& Brosius, 2000). The vivid characteristic is in contrast to unattractive attributes of pallid stimuli. Vividness can come from the power of the language used, the imagery value or the emotional value of the stimuli. Salience, on the other hand, refers to those stimuli that draw more attention to others due to their unusualness that sticks out. Both of these concepts are hard to measure (Brosius, 2003). Little research, however, focuses solely on the affective aspect of exemplars. This study, therefore, represents an initial step investigating the effects of affective exemplars in election coverage. Research in psychology has shown that affective stimuli influence attention, perception, memory, judgment and decision making (Cacioppo \& Gardner, 1999), making them highly pertinent in political coverage.

\section{Affect}

Affect is an important component in the political process, so much so that it can make or break a political life (Shields $\&$ MacDowell, 1987). The political arena also presents an ideal situation for investigating affective effects as opinions about political candidates are often polarized and affectladen. Bucy (2000), for example, found that valence of a leader's emotional display to be particularly influential in predicting trait attributions. A previous study also indicated that affect has played a major role in leader evaluation (Bucy \& Newhagen, 1999).

Affective experiences have often been described using a dimensional conceptualization - that is, categorizing any specific felt affect in terms of a common set of substrates. A long history of psychological research identifies the two primary factors common to all emotional experience as valence polarization-how positive or negative the experience is---and arousal level, or how much the emotional system is activated by the experience (Bradley, 1994).

A group of researchers (Hullett, Louden, \& Mitra, 2003) assessed the usefulness of voters' emotions toward presidential candidate in predicting voter attitude and learning. They found that the most parsimonious bi-polar model, in which affect is depicted as ranging from intensely positive to intensely negative, to have the most consistent predicting power. The valence of a voter's affective response toward a candidate is positively correlated with attitudes toward the candidate. The valence dimension along is sufficient in predicting participants' reactions to political candidates. (Marcus \& MacKuen, 1993).

\section{Affinity}

The projection that good news about a political candidate induces positive reaction to the candidate and that bad news evokes negative feelings, however, is too simple and untenable. The expectation of such affective congruence between news revelation and audience reaction does not take into account the affective dynamics.
Research on empathic reactivity offers compelling evidence that affective reactions are a function of a person's dispositions toward the agents to whom positive or negative things are happening and who reacts positively or negatively to these happenings (Eisenberg \& Strayer, 1987). In other words, the amount of affinity a person holds towards the agent interferes with the affective reaction the person expresses. When affinity is strong, persons respond in affectively compatible manner to the good or bad fortunes of others, that is, they will be pleased if positive things happen to people they like and displeased when negative things happen. When affinity is weak, persons respond counterempathically, that is, people will be pleased when bad things happen to people they don't like and displeased when good things happen to them. A study on how disposition affects viewers' reaction to news characters confirmed this prediction (Zillmann, Taylor, \& Lewis, 1998). Apparently a voter's affinity, whether he/she endorses or disapproves a candidate, also plays a role in how the voter reacts to positive and negative content about the candidate in the news.

Taken these literatures together, it can be inferred that in a political story, several factors may influence the affective reaction of audience members. Foremost among them are the political candidates, for being the persons they are and the values and goals they represent. Apparently different candidates induce different affective reactions. Secondly, the valence of the story, whether a story contains positive or negative content about a particular candidate, plays a role in audience affective reaction. But this role is mediated by the affinity of the audience members towards the candidates. If this assumption about disposition and its relationship toward agents of affect holds, the following hypotheses can be proposed:

Hypothesis 1: Different candidates generate different affective reactions.

Hypothesis 2: Valence of story content generate different affective reactions.

Hypothesis 3: When affinity is high, valence of the story is positively correlated to valence of the affective reactions such that when a news story reports positively on a wellliked candidate, affective reaction is also positive and when a news story reports negatively on a well-liked candidate, affective reaction is also negative.

Hypothesis 4: When affinity is low, valence of the story is negatively correlated to the valence of the affective reaction such that when a news story reports positively on a lessliked candidate, affectively reaction tends to be negative and when a news story reports negatively on a less-liked candidate, affectively reaction tends to be positive.

As discussed earlier, exemplars are often vivid and salient events or persons, they have more affective potential than non-exemplar stories (Zillmann, 1999). However, no research so far has supplied any evidence that exemplars has the ability to generate affective reaction. The following research question is thus proposed:

Research Question 1: Do exemplars generate more affective reactions than non-exemplars? 
The use of exemplars are often encouraged and practiced. A content analysis of the US media, for example, found exemplars to be abundant (Gibson et. al., 1994), obviously for its perceived ease in information processing and for its concreteness. Also, reporters who go the extra mile in relating the story to the audiences are often praised for their professionalism. Because no studies have been conducted on exemplars' effect on these variables, this study proposes the following additional research questions:

Research Question 2: Do exemplars affect perceived informativeness of the story?

Research Question 3: Do exemplars affect perceived believability of the story?

Research Question 4: Do exemplars affect perceived professionalism of the story?

\section{METHODOLOGY}

\section{Design}

This study used a repeated-measures $2 \times 2 \times 2 \times 8$ factionally factorial experiment. The four factors of this experiment were exemplification (exemplars and no exemplars), candidates (Bush, Kerry), valence (positive and negative) and eight news stories, held as a repeated measure.

Four presentation orders were created to randomize primacy, recency, and other order effects. Participants were assigned to only one experimental order. Exemplification, candidate and valence were within subject factors. Order of presentation was the only between subject factor. In other words, all participants saw the same eight stories, thus participants served as their own control.

\section{Materials}

All eight stories were taped from network evening news during the 2004 presidential election beginning from the Republican primary in August to the election day in November. The study was run in late 2006 so participants' familiarity and prior exposure to the stories were rendered nonrelevant in their perception. Four stories with exemplification and four without were selected out of four months worth of election stories. Exemplars were chosen for this study based on whether the exemplars contained positive or negative assertions toward either Bush or Kerry. Efforts were made to maximize the valence manipulation of the stories. Manipulation checks using participants' ratings on whether a story was positive toward Bush or Kerry on a 7-point scale anchoring Bush and Kerry indicated that the manipulation was consistent and successful. Positive stories for Bush $(\mathrm{m}$ $=2.66$ ) is statistically different from positive stories for Kerry ( $m=5.67), t=-17.64, p<.001$.

\section{Participants}

Thirty-seven student participants from a large Southeast university took part in the experiment for extra credits. The age of participants in the experiment ranged from 20 to 29 , with a mean age of 22 . There were 22 females and 15 males. They were mostly Whites (92\%), with only $8 \%$ being Blacks. The majority of them (65\%) voted in the 2004 presidential election. More than half of the participants (58.6\%) described themselves as being very interested in politics.
Most watched network news (73\%) at least two or three times a week. Overall, participants appeared to be welleducated and informed about current events.

\section{Procedure}

Participants were randomly assigned to one of the four experimental orders. All presentations were played from the four DVD order discs on a large projection screen. Participants were run in groups of 8-10 in a classroom environment resembling a theatre.

Participants first read and signed a consent form. An experimenter explained that they would view eight news stories and answer questions about each of them. The participants first completed the front part of the experimental questionnaire which measured their demographic variables as well they affinity toward Bush and Kerry. An additional scale on their valence orientation, whether they generally feel positive or negative on the average, was also included in the first part. Data from that scale was not analyzed in the present study. They were instructed to stop when they completed the first part and wait for the stories to begin.

At the end of each story, the disc was paused and participants were instructed to give evaluative measures, first on the valence of the story, that is, whether the story is positive or negative toward Bush or Kerry, then on the informativeness, believability and professionalism of the story as well as on their own affective reaction toward the story. This procedure was repeated until all eight stories were shown and participants had completed all answers.

\section{MEASURES}

\section{Affinity}

Affinity toward Bush/Kerry was measured using a 9item, 7-point semantic differential scale. The nine items were modified from the McCroskey source credibility scale (McCroskey \& Young, 1981) by adopting two dimensions pertaining to political leaders: authoritativeness and character. These bi-polar adjectives included the following: authoritative, unintelligent, visionary, dishonest, unfriendly, pleasant, selfish, awful and virtuous. Bush and Kerry were rated in two different sets. Reliability was acceptable (alpha= .94 for Bush and .74 for Kerry).

\section{Affective Reaction}

Affective reaction was measured using 12-item, 5-point Likert scales, adopted from Zillmann, Taylor and Lewis (1998). Six of the items measured positive reaction (satisfying, amusing, hilarious, enjoyable, entertaining and inspiring) and the other six measured negative reaction (offended me, shocking, disturbed me, worried me, distressed me and depressed me). Reliability was checked against reactions to all eight stories. Except for a low alpha (.67) for the positive reaction to the first story, all others showed acceptable reliability, ranging from .70 to .93 .

\section{Story Perception}

Story perception was measured using 5-point Likert scales. Respondents were asked to indicate to what extent they agreed that the stories were informative, believable and professional. 


\section{RESULTS}

Hypothesis one tested if different candidates generated different affective reactions. Repeated measure ANOVA indicated that candidate had a main effect on positive reaction $F(1,36)=13.08, p<.001$. Post hoc analysis showed Bush drew stronger positive reaction $(m=3.63, S D=.45)$ than Kerry $(m=3.82, S D=.55), t=-3.0, p<.005$. Candidate also had an main effect on negative reaction, $F(1,36)$ $=32.53, p<.001$. Post hoc analysis showed Bush drew less negative reaction $(m=4.14, S D=.62)$ than Kerry $(m=3.80$, $S D=.63), t=4.65, p<.001$.

Hypothesis two tested if valence of story content generated different affective reactions. Repeated measure ANOVA indicated that valence had a main effect on positive reaction $F(1,36)=10.26, p<.005$. Post hoc analysis showed stories with positive affect drew weaker positive reaction $(\mathrm{m}$ $=3.63, S D=.45)$ than those with negative affect $(m=3.83$, $S D=.55), t=3.2, p<.005$. Valence also had an main effect on negative reaction, $F(1,36)=4.65, p<.05$. Post hoc analysis showed stories with positive affect drew stronger negative reaction $(m=3.92, S D=.59)$ than those with negative affect $(m=4.03, S D=.61), t=-2.16, p<.05$.

Hypothesis three tested the relationship between affinity and affective reaction such that when affinity was high, valence was positively correlated with affective response. No statistically difference was found for this hypothesis.

Hypothesis four tested the reverse effect of hypothesis three in that when affinity was low, valence of the story was negatively correlated to the valence of the affective reaction. Statistical analysis did not show any difference either.

Research question one wondered if exemplars generated more affective reactions than non-exemplars. F-test did not indicate any difference in either positive or negative reactions.

Research question two wondered if exemplars affected perceived informativeness of the story. Results did not indicate that that was the case.

Research question three wondered if exemplars affected perceived believability of the story. Statistically difference was found, $F(1,36)=6.30, p<.05$. Exemplars increased perceived believability of the stories $(m=2.04, S D=.67)$ as compared to non-exemplars stories $(m=2.24, S D=.67), t=$ $2.51, p<.05$.

Research question four wondered if exemplars affected perceived professionalism of the story. No statistically difference was found.

\section{CONCLUSIONS AND DISCUSSION}

Affective reaction is a little researched area in political communication. Because affective responses can reliably predict attitude and perception of political issues and candidates (Hullett et al., 2003), more efforts are needed to unravel factors influencing such responses.

Results of this study indicated that the candidates and the valence of stories both generated different affective responses. For the participants of this study, Bush generated more positive and less negative responses than Kerry. In a larger context, this attests to the importance of choosing a viable candidate who appeals to a wide political constituent. Valence of the story, on the other hand, had the potential to induce both positive and negative affects. The more interesting findings, however, seemed to lie in the counter-intuitive fact that negative stimuli generated stronger positive affect than positive stimuli. This was perhaps due to the fact that as consumers, we are more used to seeing negative stimuli than positive ones in the news (Newhagen \& Reeves, 1992). As such, negative stories, fulfilling the surveillance function of news (Gans, 1979), were perceived to be more informative and thus enjoyable for its perceived consequences and utility, whereas the presentation of positive stories appeared to be less important, making them less enjoyable and satisfying.

Affinity is an important concept to explore. However, evidence in this study did not support the assertion that affinity induced affective responses. Theoretically, the disposition of person strongly influences affective responses. The nonsignificance findings in this study could be attributed to three factors. Firstly, the number of participants in this study was small, limiting the power of exploration. Secondly, the measurement of affinity along the two dimensions of authoritativeness and character might not be adequate. A more comprehensive scale factoring in sociability, shared ideology and competence might do a better job of capturing the variance of this variable. Thirdly, there might be a difference between affinity to a character than affinity to a political candidate, who often is a symbol of ideology. It is possible that the lack of affinity may still induce positive reaction toward a political candidate. In other words, politics may be an area where rationality plays a bigger role than affect.

The use of exemplars were often found to influence judgment and evaluations of issues. The dependent variables designed in this experiment, namely, affective response and story perception, were new to exemplar research. Results indicated that the use of exemplars only affected perceived believability of the stories, probably due to the vividness nature of exemplars. This may indicate that at least in the realm of political communication, exemplars do not show any effects in mediating audience affect. In practice, this may be good news for journalists who try to make complex political issues easy to understand.

\section{REFERENCES}

Bradley, M. M. (1994). Emotional memory: A dimensional analysis. In S. Goozen, N. Ven de Poll \& J. A. Sergeant (Eds.), Emotions: Essays on emotion theory (pp. 97-134). Hillsdale, NJ: Erlbaum.

Brosius, H. (2003). Exemplars in the news: A theory of the effects of political communication. In J. Bryant, D. Roskos-Ewoldsen \& J. Cantor (Eds.), Communication and emotion: Essays in honor of Dolf Zillmann. Mahwah, NJ: Erlbaum.

Bucy, E. P. (2000). Emotional and evaluative consequences of inappropriate leader displays. Communication Research, 27(2), 194-226.

Bucy, E. P., \& Newhagen, J. E. (1999). The emotional appropriateness heuristic: Processing televised presidential reactions to the news. Journal of Communication, 49(4), 59-79.

Cacioppo, J. T., \& Gardner, W. L. (1999). Emotion. Annual Reviews: Psychology, 50, 191-214.

Eisenberg, N., \& Strayer, J. (Eds.). (1987). Empathy and its development. Cambridge: [7] Cambridge University Press.

Eysenck, M. W. (2001). Principles of cognitive psychology (2 ed.). East Sussex, UK: Psychology Press.

Gans, H. (1979). Deciding what is news. New York: Vintage.

Gibson, R., \& Zillmann, D. (1994). Exaggerated versus representative exemplification in news reports: Perception of issues and personal consequences. Communication Research, 21(5), 603-624. 
Hansen, G., \& Benoit, W. (2007). Communication forms as predictors of issue knowledge in presidential campaigns: A meta-analytic assessment. Mass Communication and Society, 10 (2), 189-210.

Hullett, C. R., Louden, A., \& Mitra, A. (2003). Emotion and political cognition: A test of bipolar, two-dimensional, and descrete models of emotion in predicting involvement and learning. Communication Monographs, 70(3), 250-263.

Just, M. (1996). Crosstalk: Citizens, candidates, and the media in a presidential campaign. Chicago: The University of Chicago Press.

Marcus, G., \& MacKuen, M. (1993). Anxiety, enthusiasm, and the vote: The emotional underpinnings of learning and involvement duirng presidential campaigns. American Political Science Review, 87, 672685.

McCroskey, J. C., \& Young, T. J. (1981). Ethos and credibility: the construc and its measurement after three decades. Central State Speech Journal, 32, 24-34.

Newhagen, J., \& Reeves, B. (1992). The evening's bad news: Effects of compelling negative television news images on memory. Journal of Communication, 42, 25-42.
Perry, S., \& Gonzenbach, W. (1997). Effects of news exemplification extended: Considerations of controversiality and perceived future opinion. Journal of broadcasting \& Electronic Media, 41(2), 229244.

Pfau, M. (2002). The subtle nature of presidential debate influence. Argumentation \& Advocacy, 38 (4), 251-261.

Shields, S., \& MacDowell, K. (1987). "Appropriate" emotion in politics: Judgments of a Televised Debate. Journal of Communication, $37(2), 78-89$.

Zillman, D. (2006). Exemplification effects in the promotion of safety and health. Journal of Communication, 56, S221-S237.

Zillmann, D., \& Brosius, H. (2000). Exemplification in communication. Mahwah, NJ: Erlbaum.

Zillmann, D., Perkins, J. W., \& Sundar, S. S. (1992). Impression-formation effects of printed news varying in descriptive precision and exemplifications. Mediapsychologie, 4, 168-185.

Zillmann, D., Taylor, K., \& Lewis, K. (1998). News as nonfiction theater: How dispositions toward the public cast of characters affect reactions. Journal of broadcasting \& Electronic Media, 42(2), 153-169.

(c) Shuhua Zhou; Licensee Bentham Open.

This is an open access article distributed under the terms of the Creative Commons Attribution License (http://creativecommons.org/license/by/2.5/), which permits unrestrictive use, distribution, and reproduction in any medium, provided the original work is properly cited. 